\title{
Effect of $2 \%$ Chlorhexidine on Dentin Shear Bond Strength of Different Adhesive Systems: A 6 Months Evaluation
}

\author{
Efecto de la Clorhexidina al $2 \%$ Sobre la Resistencia al Cizallamiento \\ de Diferentes Sistemas Adhesivos: Una Evaluación de 6 Meses
}

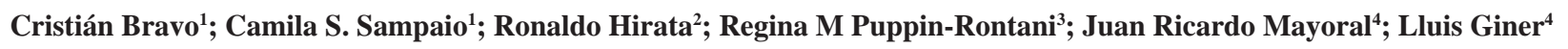

BRAVO, C.; SAMPAIO, C. S.; HIRATA, R.; PUPPIN-RONTANI, R. M. ; MAYORAL, J. R. \& GINER, LL. Effect of $2 \%$ chlorhexidine on dentin shear bond strength of different adhesive systems: A 6 months evaluation. Int. J. Morphol., 35(3):1140-1146, 2017.

SUMMARY: This study evaluated the effect of chlorhexidine dentin treatment on shear bond strength (SBS) of adhesive systems after different storages. The work included 144 third molars that had their dentin exposed and were divided in 6 groups: G1 (ASB+CHX: Adper Scotchbond 1XT + chlorhexidine $2 \%$ prior Primer); G2(ASB); G3 (APP+CHX: Adper Prompt L-Pop + CHX); G4(APP); G5 (SBU+CHX: Single Bond Universal $+\mathrm{CHX}$ ); and G6(SBU). Resin build-up was performed and teeth were subdivided regarding storage times (n=8): 72 h, 3 and 6 months. Next, SBS test was performed. At 72 hours, all equivalent groups (same adhesive system, different dentin treatment) showed no significant difference in SBS ( $\geq .05)$. Self-etch adhesive groups (with or without $\mathrm{CHX}$ ) presented lower SBS compared to other systems (P $\leq .05)$. After 3 and 6 months, all CHX-treated groups presented significantly higher SBS compared to equivalent non-treated groups ( $\mathrm{P} \leq .05)$. For both storage times, Single Bond Universal presented the highest SBS values within the same dentin treatment $(\mathrm{P} \leq .05)$, while Adper Scotchbond and Adper Prompt-L-Pop were not significantly different among them, also within the same dentin treatments [3 months (with $\mathrm{CHX}$ : $\mathrm{P}=.966$; without: $\mathrm{P}=.958$ ) and 6 months (with $\mathrm{CHX}: \mathrm{P}=.887$; without: $\mathrm{P}=.990$ )]. $\mathrm{CHX}$ Dentin disinfection is indicated for all classes of adhesives studied.

KEY WORDS: Shear bond strength; Dentin bond strength; Chlorhexidine; Adhesive systems; Adhesion.

\section{INTRODUCTION}

Although bonding to enamel is already well established in literature, the durability between dentin and adhesive systems within hybrid layers may not be that long and stable (Breschi et al., 2008; Leitune et al., 2011; Osorio et al., 2013), and has been shown to be multifactorial in nature. Long-term studies had proved that bond strength of resin-bonded dentin decreased over time due to collagen degradation (De Munck et al., 2003; Koshiro et al., 2004; Breschi et al., 2010).

Degradation of hybrid layer can occur due to a series of factors. Among them, many researches had been focused on activation of endogenous matrix metalloproteinases (MMPs) (Hebling et al., 2005; De Munck et al., 2009; Breschi et al., 2010; Leitune et al.; André et al., 2015; Li et al., 2015). MMPs are a group of zinc-calcium-dependent enzymes that regulate the physiological ad pathological mechanisms of collagen-based tissues (Chaussain-Miller et al., 2006). Although they are present in their latent form within the dentin substrate (Pashley et al., 2004), when the inorganic scaffold surrounding the collagen fibrils of dentin is missing due to caries and/or acid etching, collagen fibers become denuded and express MMP activity, beginning the degradation process (Chaussain-Miller et al.).

In order to inactivate MMPs and/or improve dentin bond strength, different strategies have been proposed (Dalkilic et al., 2012; Hirata et al., 2016). The most commonly recommended is the application of CHX to dentin (Hebling et al.; Li et al.; Ercan et al., 2009; Hiraishi et al., 2009; Breschi et al., 2010; Leitune et al.; Osorio et al.; Mohammed et al., 2014; Da Silva et al., 2015). CHX has an

\footnotetext{
${ }^{1}$ College of Dentistry, Universidad de los Andes, Santiago, Chile.

${ }^{2}$ New York University College of Dentistry, New York, USA.

${ }^{3}$ University of Campinas - Piracicaba Dental School, Piracicaba, SP, Brazil.

${ }^{4}$ College of Dentistry, Universitat Internacional de Catalunya, Barcelona, Spain.
} 
inhibitory effect on endogenous collagenolytic MMPs activity (Hebling et al.), so, it has beneficial effects on preserving dentin bond strength, and a broad spectrum of action against both Gram-positive and Gram-negative microbes (Christensen et al., 2002).

However, chlorhexidine pre-treatment can be a problem if it interferes with the bonding procedures and application of adhesive resin to dentine. Generally, a potential problem in using a disinfectant before dentin bonding agents is the possibility of an adverse effect on the bond strength of composite resins (Da Silva et al.; Ercan et al.; Hiraishi et al.).

Another issue of great importance among the several factors that may interfere with the bonding quality remains on the type of adhesive systems used. During the bonding procedure with etch-and-rinse adhesive systems, dentin is demineralized by phosphoric acid (Leitune et al.; Pashley et al., 2011). This process exposes a dense layer of fibrils of the organic matrix composed primarily of type I collagen and proteoglycan, which must be completely infiltrated with adhesive resin to form the hybrid layer (Carrilho et al., 2007; Stanislawczuk et al., 2009), a hard task to be achieved due to the organic nature of dentin. The incomplete impregnation of collagen fibers and the need for protection against the degrading mechanisms present in the oral cavity environment, led to the development of the second category, an adhesive using the self-etch strategy (Van Meerbeek $e t$ al., 2011). In this strategy, there is no need of applying a preliminary phosphoric acid gel on dental substrates, as dentine demineralization and priming occur simultaneously. Dissolved hydroxyapatite crystals and residual smear layer are then incorporated in the hybridized complex (De Munck et al., 2005). Considering the differences in professional judgment regarding selection of the adhesive strategy and number of steps, some manufacturers have released more versatile adhesive systems that include etch-and-rinse (two step) and self-etch (one or two step) options, the so called 'universal' adhesive systems (Muñoz et al., 2013).

Discrepant results are found regarding dentin bond strength of different adhesive systems after the use of CHX. Its use has been shown to either increase (Hebling et al.; De Munck et al., 2005; Breschi et al., 2010; Leitune et al.; Li et al., Mohammed Hassan et al., 2014) or decrease (Ercan et al.; Hiraishi et al.; Da Silva et al.) dentin bond strengths. Moreover, acid etching showed to activate MMPs in dentin, which occurs differently when an acid-etching is directly put in contact to dentin or when 'strong' self-etching adhesives get in contact with it (Nishitani et al., 2006; De Munck et al., 2009; Osorio et al.). These discrepancies make this a subject of great interest in restorative dentistry and warrants investigation.
Thus, this study aimed to evaluate the effect of using a CHX dentin disinfecting solution after different periods of storage times ( $72 \mathrm{~h}, 3$ months and 6 months) on the shear bond strength of different types of adhesive systems; one etch-and-rinse, one self-etch and one universal. Hypothesis tested were that 1- CHX dentin treatment would result in higher shear bond strength values when compared to groups without dentin treatment; 2- different adhesive systems would result in different shear bond strength values; and 3increased storage times would result in decreased shear bond strength values.

\section{MATERIAL AND METHOD}

One hundred and forty-four sound and freshly extracted human third molars were used. Teeth were obtained according to protocols approved by an Institutional Review Board, cleaned and stored in distilled water at room temperature until their use.

Teeth were mounted in acrylic resin to facilitate sample preparation. Roots were removed and crowns were sectioned with a low-speed diamond disk saw under watercooling to expose mid-coronal dentin. Exposed surfaces were abraded in a semi-automatic polishing machine (IsoMet 1000, Buehler, Lake Bluff, IL, USA) with 620 grit silicon carbide abrasive paper under water-cooling, in order to standardize smear layer.

Following adhesive systems were used: one etch-andrinse (ASB, Adper Scotchbond 1XT, 3M Oral Care, St. Paul, MN, USA), one self-etch (APP, Adper Prompt L-Pop, 3M Oral Care) and one universal (SBU, Single Bond Universal, 3M Oral Care), each of them being used with and without a previous dentin treatment with a cavity disinfectant (CHX, $2 \%$ Chlorhexidine, Cavity Cleanser, Bisco, Inc., Schaumburg, IL, USA), applied for $20 \mathrm{~s}$.

Teeth were then randomly divided in six groups $(\mathrm{n}=$ 24 each): G1-ASB+CHX; G2-ASB; G3-APP+CHX; G4APP; G5-SBU+CHX; G6-SBU. All groups were restored with the same resin composite (Filtek Z350, 3M Oral Care).

Application protocol for each group was performed as follows: $\mathrm{G} 1(\mathrm{ASB}+\mathrm{CHX})$ - dentin etch for $15 \mathrm{~s}$ ( $37 \%$ ScotchBond Etchant, 3M Oral Care), water rinse for $30 \mathrm{~s}$ and gently dried with a cotton pellet. Application of CHX with a micro brush for $20 \mathrm{~s}$ and lightly air-dried for $10 \mathrm{~s}$. Application of the single-component adhesive Adper Scotchbond 1XT followed by light-polymerization (Bluephase G2, Ivoclar Vivadent, Schaan, Liechtenstein) 
according to manufacturer's instructions. Resin composite was incrementally built-up through a disc with a central orifice $(\varnothing=3.0 \mathrm{~mm}$ and $4 \mathrm{~mm}$ high), which was centered on the tooth to obtain the standardized composite bar for the test ( 2 increments, $2 \mathrm{~mm}$ each) with Filtek Z350 XT, each layer being light-polymerized for 20s (Bluephase G2); $\mathrm{G} 2$ (ASB) - G2 followed the same steps previously described for G1, except for the application of CHX; G3(APP+CHX) - Application of $\mathrm{CHX}$ as previously described, application of the self-etch adhesive system Adper Prompt L-Pop followed by light-polymerization according to manufacturer's instructions. Resin composite build-up was performed following the same steps previously described for G1. G4(APP) - G4 followed the same steps previously described for G3, except for the application of CHX; G5(SBU+CHX) - Application of CHX as previously described, application of the universal adhesive system followed by light-polymerization according to the self-etch protocol of the manufacturer's instructions. Resin composite build-up was performed following the same steps previously described for G1. G6(SBU) - G6 followed the same steps previously described for G5, except for the application of CHX.

After restorative procedures, each group was subdivided into 3 subgroups, according to different storage times ( $\mathrm{n}=8$ each): 72 hours, 3 months and 6 months. Teeth were stored in distilled water at room temperature.

Shear Bond Strength Test. After the designated storage time period, each specimen was placed in a universal testing machine (Z100, Zwick Roell, Germany) and shear bond strength was measured at a crosshead speed of $0.5 \mathrm{~mm} /$ min. The shear bond strength of composite resin to dentin was recorded in Newtons (N) and calculated in MPa taking into account the cross-sectional area of the composite buildup.

Stereoscopic Microscopy and Scanning Electronic Microscopy. After the shear bond strength testing procedure, fractured surfaces were examined in a stereoscopic microscope to identify the types of failures, which were classified as: adhesive (failure between tooth and restoration material), mixed (both cohesive and adhesive), cohesive in dentin (failure within dentin) or cohesive in composite (failure within resin composite restoration). Some specimens weresputter coated with gold and prepared for SEM examination (JSM-5600LV, JEOL, Tokyo, Japan), with different magnifications to analyze the hybrid layers among the different adhesive systems. Hybrid layers were exposed with a slow speed saw and dentin was dissolved by sequential rinses in hydrochloric acid and sodium hypochlorite to reveal resin penetration.
Statistical Analysis. One-way ANOVA and Tukey post-hoc tests were conducted to compare the groups with and without CHX treatment of each separate adhesive protocol, at each storage time $(\mathrm{a}=.05)$.

\section{RESULTS}

Shear bond strength means of the different adhesive systems and different storage times, according to CHX dentin treatment, are shown in Table I. Statistical tests revealed difference between groups when evaluated storage times (72 hours, 3 months and 6 months; $\mathrm{P} \leq .05)$. Statistical difference evaluated dentin treatment with $\mathrm{CHX}(\mathrm{P} \leq .05)$, and adhesive systems $(\mathrm{P} \leq .05)$ was also observed.

CHX dentin treatment proved to increase shear bond strength for all adhesive systems after 3 and 6 months storage times. After 72 hours, no adhesive systems showed statistical difference, even with the use of CHX, although CHX dentin treatment slightly increased the values for groups 1 $(\mathrm{ASB}+\mathrm{CHX})$ and $3(\mathrm{APP}+\mathrm{CHX})$. For all storage times, group 4 (APP) showed the lowest values of shear bond strength.

At 72 hours, none of the equivalent groups (same adhesive system, comparing $\mathrm{CHX}$ dentin treatment) presented significant differences in shear bond strengths ( $P$ $\leq .05)$. When different adhesive systems were compared within this period of storage time, groups 1 (ASB+CHX), 2 (ASB), 5 (SBU+CHX) and 6 (SBU) presented the highest values of shear bond strength, not being significantly different between each other ( $\mathrm{P} \geq 0.05$ ). Groups from the self-etching adhesive system Prompt-L-Pop presented the lowest values, although the use of CHX increased them. Group 3 (APP+CHX) were not significantly different than groups 2 (ASB), 5 (SBU+CHX) and 6 (SBU) $(\mathrm{P} \geq .05)$. Group 4 (APP) presented the lowest shear bond strengths, although not different than group $3(\mathrm{APP}+\mathrm{CHX})(\mathrm{P}=.862)$.

After 3 months storage time period, all equivalent groups (same adhesive system, comparing CHX treatment) presented higher values when CHX treatment was applied ( $\mathrm{P}$ $\leq .05$ ). Moreover, when evaluating different adhesive systems after CHX dentin treatment, G5 (SBU+CHX) presented the highest values of shear bond strength, significantly different than G1 (ASB+CHX) $(\mathrm{P}=.000)$ and G3 $(\mathrm{P}=.000)$. Groups 1 and 3 were not significantly different between each other $(\mathrm{P}=$ .966). When evaluating non-CHX dentin treated groups, again the Universal adhesive system (G6 - SBU) presented the highest bond strength values, significantly different than $\mathrm{G} 2$ $(\mathrm{ASB})(\mathrm{P}=.000)$ and $\mathrm{G} 4(\mathrm{APP})(\mathrm{P}=.000)$. Groups 2 and 4 were not different between each other $(\mathrm{P}=.958)$. 
Table I: Shear bond strength means (standard deviation) from different groups concerning different storage times.

\begin{tabular}{lccr}
\hline & \multicolumn{1}{c}{72 hours } & \multicolumn{1}{c}{3 months } & \multicolumn{1}{c}{6 months } \\
\hline G1 - ASB + CHX & $28.98(4.99) \mathrm{Aa}$ & $20.91(4.57) \mathrm{Cb}$ & $16.57(1.19) \mathrm{Bb}$ \\
G2 - ASB & $24.87(3.20) \mathrm{ABa}$ & $12.42(4.32) \mathrm{Db}$ & $8.05(2.33) \mathrm{Dc}$ \\
$\mathrm{G} 3-\mathrm{APP}+\mathrm{CHX}$ & $19.43(6.08) \mathrm{BCa}$ & $22.66(5.30) \mathrm{BCa}$ & $17.59(2.19) \mathrm{Ba}$ \\
$\mathrm{G} 4-\mathrm{APP}$ & $17.13(3.56) \mathrm{Ca}$ & $14.26(3.66) \mathrm{Da}$ & $7.48(1.13) \mathrm{Db}$ \\
$\mathrm{G} 5-\mathrm{SBU}+\mathrm{CHX}$ & $24.61(2.68) \mathrm{ABb}$ & $38.78(4.18) \mathrm{Aa}$ & $22.71(1.89) \mathrm{Ab}$ \\
G6 - SBU & $25.39(2.38) \mathrm{ABa}$ & $28.28(4.04) \mathrm{Ba}$ & $11.70(2.21) \mathrm{Cb}$
\end{tabular}

*Means followed by different letters (upper cases in columns and lower cases in rows) were statistically different $(\mathrm{p} \leq 0.05)$.

When 6 months storage time was evaluated, results from the adhesive systems without the use of CHX dropped more drastically for all groups, and all adhesive systems showed decreased results when CHX was not applied ( $\mathrm{P} \leq$ $.05)$. The Universal adhesive system presented higher shear bond strengths values either when dentin was treated with CHX or not $(\mathrm{P} \leq .05)$. Regarding the CHX-treated groups, G5 ( $\mathrm{SBU}+\mathrm{CHX})$ presented the highest bond strengths, significantly different than the other CHX-treated groups ( $\mathrm{P} \leq$ $.05)$. Groups $1(\mathrm{ASB}+\mathrm{CHX})$ and $3(\mathrm{APP}+\mathrm{CHX})$ were not significantly different between each other $(\mathrm{P} \leq .0887)$. When non-CHX treated groups were evaluated, G6 (SBU) presented the highest shear bond strengths, significantly different than G2 (ASB) (P = .005) and G4 (APP) (P=.001). G2 and G4 did not present statistical significant difference $(\mathrm{P}=.990)$.
Regarding the same group within different storage times, most of the groups presented a significant decrease in shear bond strength after 3 and 6 months $(\mathrm{P} \leq .05)$, except for $\mathrm{G} 3(\mathrm{APP}+\mathrm{CHX})$, that did not show statistical difference between the different periods of time $(\mathrm{P} \geq .05)$. Group 1 $(\mathrm{ASB}+\mathrm{CHX})$ presented a decrease in SBS after 3 and 6 months, being statistically different than $72 \mathrm{~h}(\mathrm{P} \leq .05)$, but not different between each other $(\mathrm{P}=.096)$. G2 (ASB) presented a significant decrease from $72 \mathrm{~h}$ to 3 months $(\mathrm{P}=$ $.000)$ and also from 3 to 6 months (P = .044). Groups 4 (APP) and 6 (SBU) only showed a decrease after 6 months, statistically different than $72 \mathrm{~h}$ and 3 months storage times $(\mathrm{P} \leq .05)$. Group 5 (SBU+CHX) presented a different pattern, and results after 3 months were significantly higher compared to $72 \mathrm{~h}(\mathrm{P}=.000)$ and 6 months $(\mathrm{P}=.000)$.

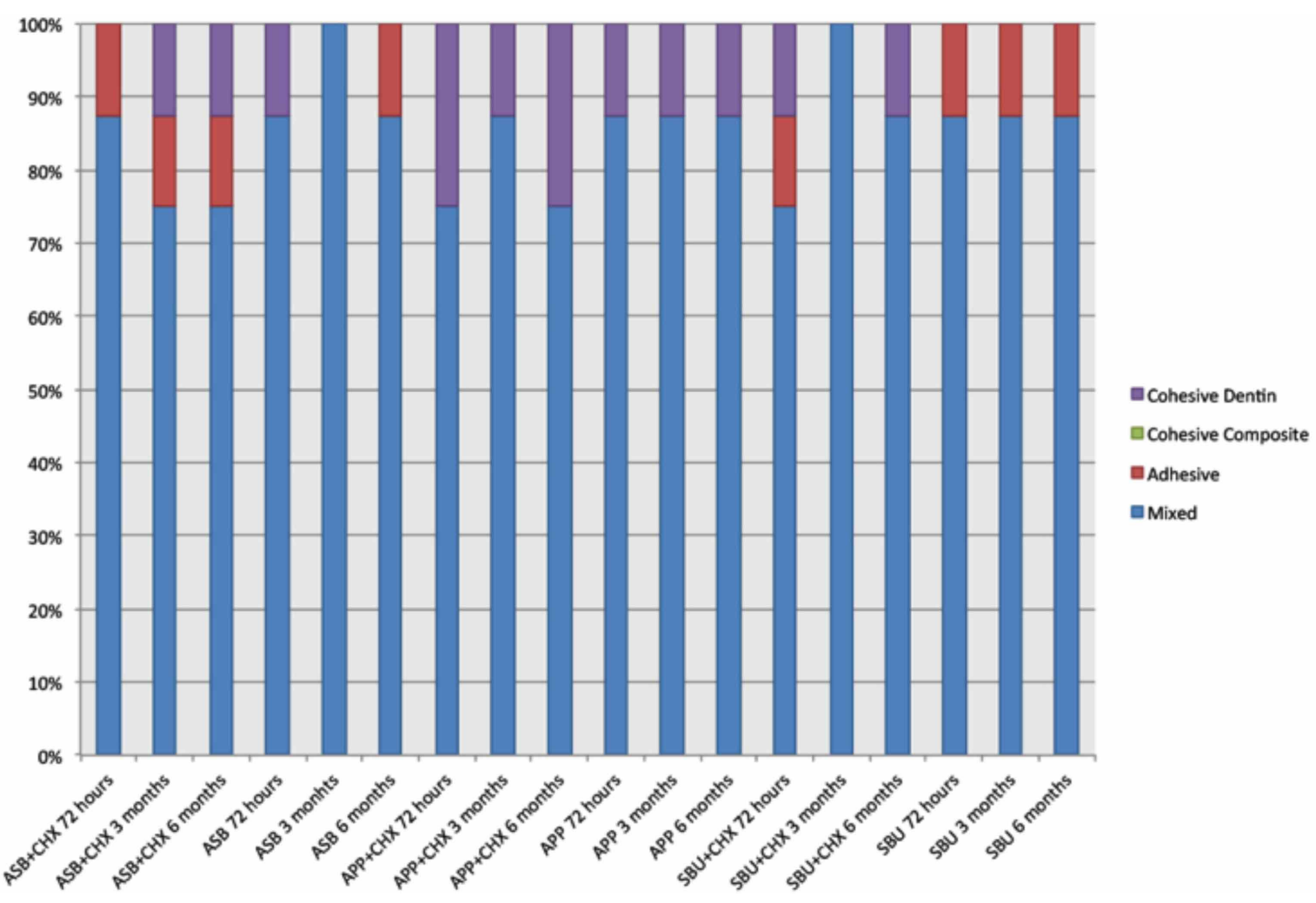

Fig. 1. Distribution of failure patterns among the different adhesive system groups, regarding storage times and CHX dentin treatment. 
When evaluating failure patterns, whatever the storage time or CHX application evaluated, mixed failures were the most observed within groups, ranging from 75$100 \%$. Cohesive failure in dentin was the second most

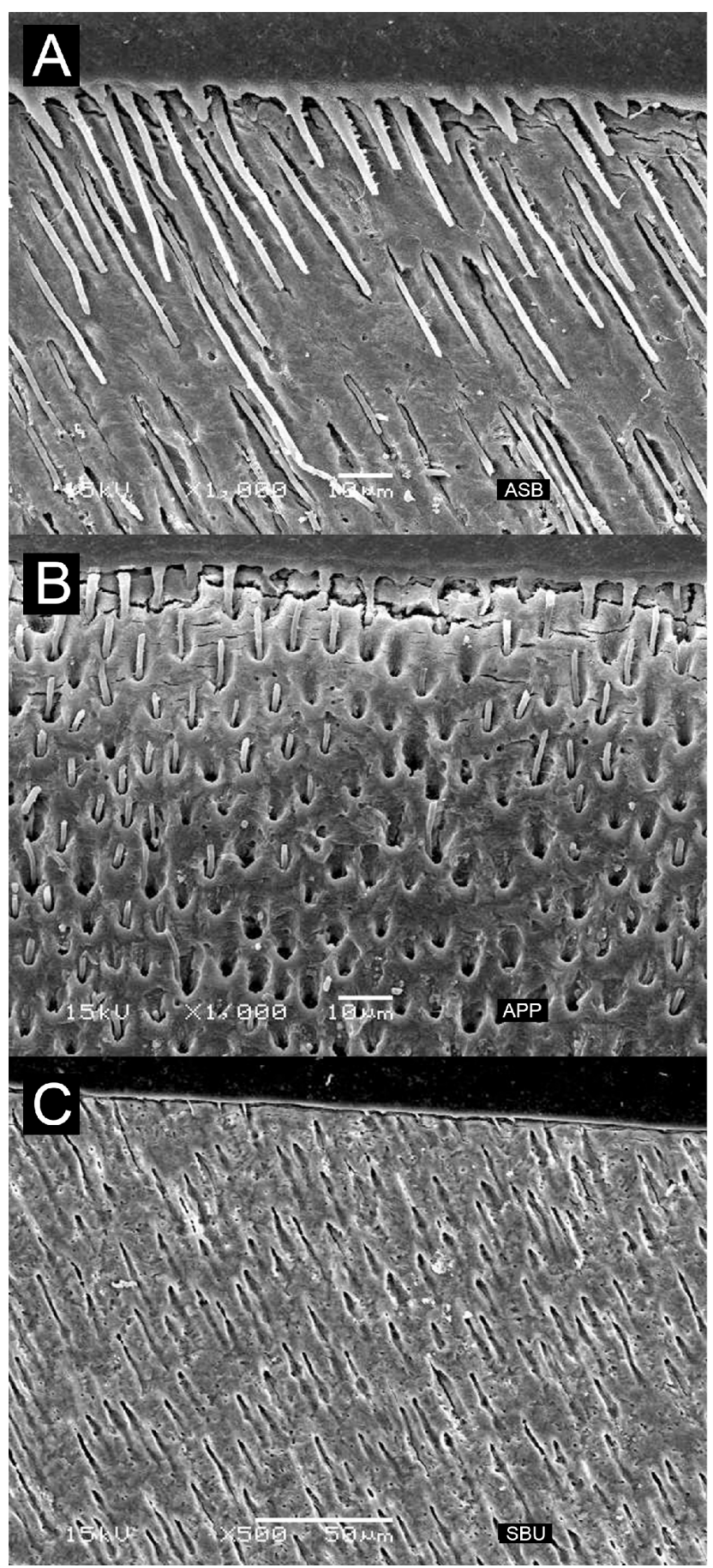

Fig. 2. SEM micrographs of the (A) etch-and-rinse (ASB), (B) selfetch (APP) and (C) universal (SBU) adhesive systems used in this study. The difference within the resin tags can be observed among the different adhesive systems (the more acidic the treatment, the deeper the adhesive penetrated). observed, ranging from 0-25\%. Adhesive failure ranged from $0-12.5 \%$, and cohesive failure in composite was not observed (Fig. 1). Scanning electronic microscopy images depicted longer resin tags for the etch-and-rinse adhesive system (ASB), followed by the 'strong' self-etch adhesive system (APP), and only a smear layer interaction for the universal adhesive (SBU) (Fig. 2).

\section{DISCUSSION}

Until nowadays, with novel adhesive systems, dentin bonding remains difficult because of its unique organic nature. In order to develop increased bond strength and decreased bonding degradation, different approaches have been studied (Dalkilic et al.; Hirata et al.), such as dentin CHX application (Hebling et al.; Breschi et al., 2010; Leitune et al.; Li et al.; Mohammed Hassan et al.; Carrilho et al.). In our study, the dentin treatment with CHX resulted in higher shear bond strength for all groups of dentin adhesive systems after 3 and 6 months, although after 72 hours, the values comparing CHX-treated or non-treated groups remained statistically insignificant, thus partially accepting the first hypotheses. Dentin treatment with $\mathrm{CHX}$ has shown distinct results in the literature. Among the contradictory results related to $\mathrm{CHX}$ application in dentin, studies had shown a decrease in bond strength after CHX application (Da Silva et al.; Ercan et al.; Hiraishi et al.), while others showed the opposite results (Hebling et al.; Breschi et al., 2010; Leitune et al.; Li et al.; Mohammed Hassan et al.; Carrilho et al.). In our study, the use of this disinfectant on dentin treatment proved to be effective in improving the shear bond strengths of simplified dentin adhesive systems, going in accordance to several other studies (Hebling et al.; Breschi et al., 2010; Leitune et al.; Li et al.; Mohammed Hassan et al.).

$\mathrm{CHX}$ is an amphiphilic molecule that binds to various proteins by a cation-chelation mechanism, and may inhibit the catalytic activity of MMPs by binding with $\mathrm{Zn}+2$ or $\mathrm{Ca}+2$ (Breschi et al., 2010). CHX has proved to significantly lower the loss of bond strength and nanoleakage seen in acid-etched resin-bonded dentin artificially aged for 2 years (Breschi et al., 2010). The use of CHX can inhibit matrix metalloproteinases (MMPs), which can be activatedvia contemporary bonding agents and auto-degradate collagen fibers within the dentin hybrid layer (De Munck et al., 2009; Osorio et al.).

Another issue that can affect the bond strength is the capability of an adhesive system to activate MMPs. Adhesive systems with higher $\mathrm{pH}$ seems to activate those enzymes less, thus showing less degradation over time (De Munck et 
al., 2009; Osorio et al.). This fact was observed in our study, accepting the second hypothesis, which showed that different adhesive systems would result in different shear bond strength values. After 3 months, whether dentin was treated with CHX or not, Single Bond Universal adhesive system presented higher shear bond strengths values, compared to other groups within the same dentin treatment. After 6 months, again, the universal adhesive system presented higher shear bond strengths values either when dentin was treated with CHX or not, compared to other adhesive systems within the same dentin treatments.

Although the adhesive system APP is presented as a self-etch approach, its $\mathrm{pH}$ is relatively low $(\mathrm{pH}=1.0)$, and in this case, after 6 months of storage time, showed results similar as the etch-and-rinse adhesive system ASB, which with uses an acid etching of also a low $\mathrm{pH}(\mathrm{pH}=0.1)$. On the other hand, the universal adhesive of $\mathrm{pH}=2.7$ showed higher values of bond strength during all time periods. Possibly, this adhesive system activated less MMPs in the dentin, thus promoting lower hybrid layer degradation (De Munck et al., 2009). It was previously shown that mild self-etch adhesive systems were less prone to release those enzymes when compared to strong self-etch adhesive systems (De Munck et al., 2009; Osorio et al.). The $\mathrm{pH}$ values can also explain the SEM images shown in this study, where the lower $\mathrm{pH}$ achieved in the dentin treatment, the deeper the resin tags. Moreover, the universal adhesive system used in this study presents 10-methacryloyloxydecyl dihydrogen phosphate monomer (MDP) in their composition, a molecule that is capable of bonding chemically to dentine (Muñoz et al.; Yoshida et al., 2012). It was shown an effective chemical interaction between MDP and hydroxyapatite, forming a stable nanolayer that could result in a stronger phase at the adhesive interface, increasing the mechanical strength of the adhesive interface (Muñoz et al.; Yoshida et al.), which can also explain the higher shear bond strength values obtained by this adhesive system, whether or not it was used with CHX. The lower results of the adhesive system APP groups even in the 72 hours storage time, compared to the other adhesive systems, can be related to its low $\mathrm{pH}$. Very low $\mathrm{pH}$ and high hydrophilicity might have a detrimental effect on the mechanical stability as a result of excessive water sorption. It was shown that its porous hybrid layer facilitates diffusion of water through the adhesive layer (Samimi et al., 2016). However, as it has been mentioned, after 6 months, this adhesive system did not present statistical difference when compared to the etch-and-rinse adhesive system groups, either when dentin was treated with CHX or not.

The third research hypotheses, that tested whether increased storage times would decrease shear bond strength was also accepted, since most of the adhesive systems groups resulted in a degradation of the shear bond strength after storage. The storage medium may simulate the time and conditions to which restorations will be exposed in the mouth, and this is of great value in the evaluation of bond strength degradation (Hashimoto et al., 2000). In general, water, artificial saliva and mineral oil are the media most used for storage during in vitro tests for evaluating bond strength degradation over time. These results go in accordance with other studies, which show a significant decrease in dentin bond strength over time (Breschi et al., 2010; De Munck et al., 2009). However, groups treated with CHX presented less degradation compared to non-treated groups, in accordance to a study that showed that the use of CHX as an MMP inhibitor resulted in the arrest of the in vivo degradation of the hybrid layers after six months in an etch-and-rinse adhesive system (Hebling et al.). Long-term in vivo studies still warrants investigation in the CHX dentin treatment scenario of different types of adhesive systems.

Within the limitations of this laboratory study, it may be stated that dentin treatment with chlorhexidine increases the bond strength of different adhesive systems when evaluated in different storage times. This fact seems to be more pronounced after storage times of 3 and 6 months, respectively, while immediate 72 hours bond strength was not affected by CHX treatment. The Universal adhesive system presented higher bond strength results after 3 and 6 months, whether or not CHX dentin treatment is used. The authors highly indicate the use of CHX dentin treatment when dealing with any adhesive system.

BRAVO, C.; SAMPAIO, C. S.; HIRATA, R.; PUPPIN-RONTANI, R. M. ; MAYORAL, J. R. \& GINER, L. Efecto de la clorhexidina al $2 \%$ sobre la resistencia al cizallamiento de diferentes sistemas adhesivos: una evaluación de 6 meses. Int. J. Morphol., 35(3):11401146, 2017.

RESUMEN. Este estudio evaluó el efecto del tratamiento de la dentina con clorhexidina sobre la resistencia al cizallamiento (SBS) de sistemas adhesivos después de diferentes almacenamientos. Se removió el esmalte oclusal a 144 terceros molares y se dejó su dentina media expuesta, posteriormente se dividieron al azar en 6 grupos: G1 (ASB + CHX: Adper Scotchbond 1XT + clorhexidina $2 \%$ antes del Primer); G2 (ASB); G3 (APP + CHX: L-Pop + CHX de Adper); G4 (APP); G5 (SBU + CHX: Single Bond Universal + CHX); y G6 (SBU). Se realizó la aplicación de la resina compuesta y se subdividieron los grupos con respecto a los tiempos de almacenamiento $(n=8): 72 \mathrm{~h}, 3$ y 6 meses. A continuación, se realizó la prueba SBS. A las 72 horas, todos los grupos equivalentes (el mismo sistema adhesivo, diferentes tratamientos de dentina) no mostraron diferencias significativas en los valores de SBS ( $\mathrm{P} \geq .05)$. Los grupos de adhesivo de auto-grabado (con o sin CHX) presentaron valores de SBS más bajos en comparación con otros sistemas $(\mathrm{P} \leq .05)$. Después de 3 y 6 meses, todos los grupos tratados con CHX presentaron valores de SBS significativamente mayores en comparación con los grupos no trata- 
dos equivalentes ( $\mathrm{P} \leq .05)$. Para ambos tiempos de almacenamiento, Single Bond Universal presentó los valores de SBS más altos dentro del mismo tratamiento dentinario $(\mathrm{P} \leq .05)$, mientras que el Adper Scotchbond y el Adper Prompt-L-Pop no fueron significativamente diferentes entre ellos, también dentro de los mismos tratamientos dentinarios [ 3 meses (con CHX: $\mathrm{P}=.966$, sin: $\mathrm{P}=.958$ ) y 6 meses (con CHX: $\mathrm{P}=.887$; sin: $\mathrm{P}=.990)]$. La desinfección de la dentina con CHX está indicada para todas las clases de adhesivos estudiados.

PALABRAS CLAVE: Resistencia al cizallamiento; Adhesión dentinaria; Clorhexidina; Sistemas adhesivos; Adhesión.

\section{REFERENCES}

André, C. B.; Gomes, B. P.; Duque, T. M.; Stipp, R. N.; Chan, D. C.; Ambrosano, G. M. \& Giannini, M. Dentine bond strength and antimicrobial activity evaluation of adhesive systems. J. Dent., 43(4):466-75, 2015.

Breschi, L.; Mazzoni, A.; Nato, F.; Carrilho, M.; Visintini, E.; Tjäderhane, L.; Ruggeri, A. Jr.; Tay, F. R.; Dorigo Ede, S. \& Pashley, D. H. Chlorhexidine stabilizes the adhesive interface: a 2-year in vitro study. Dent. Mater., 26(4):320-5, 2010.

Breschi, L.; Mazzoni, A.; Ruggeri, A.; Cadenaro, M.; Di Lenarda, R. \& De Stefano Dorigo, E. Dental adhesion review: aging and stability of the bonded interface. Dent. Mater., 24(1):90-101, 2008.

Carrilho, M. R.; Geraldeli, S.; Tay, F.; de Goes, M. F.; Carvalho, R. M.; Tjäderhane, L.; Reis, A. F.; Hebling, J.; Mazzoni, A.; Breschi, L. \& Pashley, D. In vivo preservation of the hybrid layer by chlorhexidine. J. Dent. Res., 86(6):529-33, 2007.

Chaussain-Miller, C.; Fioretti, F.; Goldberg, M. \& Menashi, S. The role of matrix metalloproteinases (MMPs) in human caries. J. Dent. Res., 85(1):22-32, 2006.

Christensen, G. J. Preventing postoperative tooth sensitivity in class I, II and V restorations. J. Am. Dent. Assoc., 133(2):229-31, 2002.

Da Silva, E. M.; Glir, D. H.; Gill, A. W.; Giovanini, A. F.; Furuse, A. Y. \& Gonzaga, C. C. Effect of chlorhexidine on dentin bond strength of two adhesive systems after storage in different media. Braz. Dent. J., 26(6):6427, 2015.

Dalkilic, E. E.; Arisu, H. D.; Kivanc, B. H.; Uctasli, M. B. \& Omurlu, H. Effect of different disinfectant methods on the initial microtensile bond strength of a self-etch adhesive to dentin. Lasers Med. Sci., 27(4):819-25, 2012.

De Munck, J.; Van den Steen, P. E.; Mine, A.; Van Landuyt, K. L.; Poitevin, A.; Opdenakker, G. \& Van Meerbeek, B. Inhibition of enzymatic degradation of adhesive-dentin interfaces. J. Dent. Res., 88(12):1101-6, 2009.

De Munck, J.; Van Landuyt, K.; Peumans, M.; Poitevin, A.; Lambrechts, P.; Braem, M. \& Van Meerbeek, B. A critical review of the durability of adhesion to tooth tissue: methods and results. J. Dent. Res., 84(2):118-32, 2005.

De Munck, J.; Van Meerbeek, B.; Yoshida, Y.; Inoue, S.; Vargas, M.; Suzuki, K.; Lambrechts, P. \& Vanherle, G. Four-year water degradation of totaletch adhesives bonded to dentin. J. Dent. Res., 82(2):136-40, 2003.

Ercan, E.; Erdemir, A.; Zorba, Y. O.; Eldeniz, A. U.; Dalli, M.; Ince, B. \& Kalaycioglu, B. Effect of different cavity disinfectants on shear bond strength of composite resin to dentin. J. Adhes. Dent., 11(5):343-6, 2009.

Hashimoto, M.; Ohno, H.; Endo, K.; Kaga, M.; Sano, H. \& Oguchi, H. The effect of hybrid layer thickness on bond strength: demineralized dentin zone of the hybrid layer. Dent. Mater., 16(6):406-11, 2000.

Hebling, J.; Pashley, D. H.; Tjäderhane, L. \& Tay, F. R. Chlorhexidine arrests subclinical degradation of dentin hybrid layers in vivo. J. Dent. Res., 84(8):741-6, 2005

Hiraishi, N.; Yiu, C. K.; King, N. M. \& Tay, F. R. Effect of $2 \%$ chlorhexidine on dentin microtensile bond strengths and nanoleakage of luting cements. J. Dent., 37(6):440-8, 2009.

Hirata, R.; Sampaio, C.; Machado, L. S.; Coelho, P. G.; Thompson, V. P.; Duarte, S.; Ayres, A. P. \& Giannini, M. Short- and long-term evaluation of dentin-resin interfaces formed by etch-and-rinse adhesives on plasmatreated dentin. J. Adhes. Dent., 18(3):215-22, 2016.

Koshiro, K.; Inoue, S.; Tanaka, T.; Koase, K.; Fujita, M.; Hashimoto, M. \& Sano, H. In vivo degradation of resin-dentin bonds produced by a selfetch vs. a total-etch adhesive system. Eur. J. Oral. Sci., 112(4):368-75, 2004.

Leitune, V. C. B.; Portella, F. F.; Bohn, P. V.; Collares, F. M. \& Samuel, S. M. W. Influence of chlorhexidine application on longitudinal adhesive bond strength in deciduous teeth. Braz. Oral. Res., 25(5):388-92, 2011.

Li, H.; Li, T.; Li, X.; Zhang, Z.; Li, P. \& Li, Z. Morphological effects of MMPs inhibitors on the dentin bonding. Int. J. Clin. Exp. Med., 8(7):10793803, 2015.

Mohammed Hassan, A.; Ali Goda, A. \& Baroudi, K. The effect of different disinfecting agents on bond strength of resin composites. Int. J. Dent., 2014:231235, 2014.

Muñoz, M. A.; Luque, I.; Hass, V.; Reis, A.; Loguercio, A. D. \& Bombarda, N. H. Immediate bonding properties of universal adhesives to dentine. $J$. Dent., 41(5):404-11, 2013.

Nishitani, Y.; Yoshiyama, M.; Wadgaonkar, B.; Breschi, L.; Mannello, F.; Mazzoni, A.; Carvalho, R. M.; Tjäderhane, L.; Tay, F. R. \& Pashley, D. H. Activation of gelatinolytic/collagenolytic activity in dentin by self-etching adhesives. Eur. J. Oral. Sci., 114(2):160-6, 2006.

Osorio, R.; Yamauti, M.; Ruiz-Requena, M. E. \& Toledano, M. MMPs activity and bond strength in deciduous dentine-resin bonded interfaces. J. Dent., 41(6):549-55, 2013.

Pashley, D. H.; Tay, F. R.; Breschi, L.; Tjäderhane, L.; Carvalho, R. M. Carrilho, M. \& Tezvergil-Mutluay, A. State of the art etch-and-rinse adhesives. Dent. Mater., 27(1):1-16, 2011.

Pashley, D. H.; Tay, F. R.; Yiu, C.; Hashimoto, M.; Breschi, L.; Carvalho, R. M. \& Ito, S. Collagen degradation by host-derived enzymes during aging. J. Dent. Res., 83(3):216-21, 2004.

Samimi, P.; Alizadeh, M.; Shirban, F.; Davoodi, A. \& Khoroushi, M. Effect of dentin dehydration and composite resin polymerization mode on bond strength of two self-etch adhesives. Contemp. Clin. Dent., 7(1):16-20, 2016.

Stanislawczuk, R.; Amaral, R. C.; Zander-Grande, C.; Gagler, D.; Reis, A. \& Loguercio, A. D. Chlorhexidine-containing acid conditioner preserves the longevity of resin-dentin bonds. Oper. Dent., 34(4):481-90, 2009.

Van Meerbeek, B.; Yoshihara, K.; Yoshida, Y.; Mine, A.; De Munck, J. \& Van Landuyt, K. L. State of the art of self-etch adhesives. Dent. Mater., 27(1):17-28, 2011.

Yoshida, Y.; Yoshihara, K.; Nagaoka, N.; Hayakawa, S.; Torii, Y.; Ogawa, T.; Osaka, A. \& Meerbeek, B. V. Self-assembled Nano-layering at the Adhesive interface. J. Dent. Res., 91(4):376-81, 2012.

\author{
Corresponding author: \\ Cristián Bravo \\ Department of Biomaterials \\ College of Dentistry \\ Universidad de los Andes \\ Av Monseñor Alvaro del Portillo 12,455 \\ Las Condes, Santiago \\ CHILE
}

E-mail: cbravop@uandes.cl

Received:30-05-2017

Accepted:05-07-2017 